\title{
Pure-tone overstimulation protects surviving avian hair cells from acoustic trauma
}

\author{
Yehoash Raphael \\ University of Michigan Medical School, Kresge Hearing Research Institute, Ann Arbor, Michigan, U.S.A.
}

(Received 26 April 1990; accepted 9 December 1990)

\begin{abstract}
It was found that intense pure-tones which damage hair cells in chicks, also result in damage to the tectorial membrane (TM). This study was designed to elucidate the effects of a second pure-tone insult on hair cells which survived a priming pure-tone exposure. Chicks were exposed to a pure-tone of $1.5 \mathrm{kHz}$ at $124 \mathrm{~dB}$ SPL. Lesion was found in both TM and hair cells, but the area of damage to the TM was much larger than that to the hair cells. Following this exposure, chicks were exposed to a second intense pure-tone at $2.2 \mathrm{kHz} 124 \mathrm{~dB}$ SPL. The frequency of the second exposure corresponded to a region where the TM did, but hair cells did not appear to be injured by the first exposure. The second exposure caused significantly less hair cell damage in chicks already exposed to the $1.5 \mathrm{kHz}$ pure-tone than in controls which were not primed with the first exposure. This finding suggests that the first exposure provides a degree of protection for the surviving hair cells, perhaps by uncoupling them from the TM.
\end{abstract}

Chick; Acoustic trauma; Hair cell; Tectorial membrane; Protection; Actin

\section{Introduction}

Degeneration of the tectorial membrane (TM) following exposure to pure-tone overstimulation has been observed in the chick cochlea (Cotanche, 1987b). The mechanism of damage to the TM and the events leading to its degeneration are not known. Cotanche (1987b) has shown that immediately after acoustic trauma in the chick, many of the hair cells which remain along the margins of the damaged region are not covered by the TM. It was not made clear, however, whether the damage to the TM extended beyond the area of hair cell loss. The present investigation was carried out to compare the area of tone-induced TM damage with that of hair cell damage, and to elucidate the effects of acoustic overstimulation on hair cells which are uncoupled from the TM.

Correspondence to: Yehoash Raphael, University of Michigan Medical School, Kresge Hearing Research Institute, 1301 East Ann Street, Ann Arbor, MI 48109 0506, U.S.A. FAX: (313) 764-0014
Scanning electron microscopy (SEM) analysis was performed because it is a powerful tool to determine the surface morphology of the sensory epithelium and the TM. Light microscope (LM) sections were used to reveal the TM as well as the entire height of the epithelium. Fluorescent Phalloidin, which stains F-actin with high specificity, was used to detect early pathological changes in hair cells. Actin has been shown to depolymerize in hair cells after acoustic trauma (Saunders et al., 1985; Tilney et al., 1982). In addition, intercellular adherens junctions are actin-rich and therefore phalloidin is useful for labeling apical cell borders. The combined use of all three methods, LM, SEM and phalloidin labeling, is important in determining the condition of the epithelium. This was suggested by findings that surface morphology of traumatized guinea pig auditory epithelium cannot be reliably used to predict the condition of the hair cells (Raphael and Altschuler, 1991).

The results of this study suggest that when uncoupled from the TM, hair cells are less susceptible to damage due to acoustic overstimulation. A 
preliminary report of similar experiments has been presented (Raphael et al., 1989).

\section{Materials and Methods}

Three identical experiments were performed, each using 10 chicks. The chicks were one week old at the beginning of each experiment. They were divided into four groups in each of the three experiments:

Group 1. Controls- Two chicks, untreated.

Group 2. Priming exposure only- Two chicks were 'primed' by exposure to a $1.5 \mathrm{kHz}$ pure-tone presented at $124 \mathrm{~dB}$ SPL for $22 \mathrm{~h}$.

Group 3. Second exposure only- Two chicks were exposed to a $2.2 \mathrm{kHz}$ pure-tone at 124 $\mathrm{dB}$ SPL for $22 \mathrm{~h}$, without priming.

Group 4.Priming and second exposure- Four chicks were primed as in group 2, followed by exposure to a $2.2 \mathrm{kHz}$ puretone presented at $124 \mathrm{~dB}$ SPL for $22 \mathrm{~h}$. The interval between the first (priming) and the second exposures was $2 \mathrm{~h}$.

Pure-tones were generated by a Wavetek Model 182A signal generator, amplified by an SAE Two power amplifier Model P10 and presented in freefield through a Jensen horn Model DD-100A. Sound intensity was monitored at the onset and upon completion of each experiment with a Bruel and Kjaer Precision Sound Level Meter Type 2203 with a condenser microphone (Bruel and Kjaer).

Animals were sacrificed by decapitation 2-4 h after the exposure. The lower jaw was removed, the head bisected in the sagittal plane, and the temporal bones approached from the medial aspect. The whole temporal bone was removed from the skull, along with the middle ear tissues. The ear-drum and surrounding tissues were gently pulled away with the columella. The cochlea was removed from the bony capsule and dissected as described by Tilney et al. (1988), except that during dissection the tissue was kept immersed in the fixative. The TM was removed in most cases, but several cochleae were processed with the TM attached, to allow inspection of its structure in situ.

In each of the three experiments, half of the cochleae from each group were prepared for phalloidin labeling. The rest were again divided in two halves, one was prepared for SEM analysis and one for histology at the (LM) level.

\section{Fluorescence microscopy}

Whole-mounts were stained with phalloidin to label microfilaments. For this purpose, the cochleae were fixed for $2 \mathrm{~h}$ with $2 \%$ paraformaldehyde in $0.1 \mathrm{M}$ phosphate buffer at $\mathrm{pH} 7.35$ and permeabilized in $0.3 \%$ Triton $\mathrm{X} 100$ for 10 min. The tissue was incubated $30 \mathrm{~min}$ in rhodamine-conjugated phalloidin (Molecular Probes, OR), diluted 1:50 in PBS, rinsed and mounted in Gelvatol (Monsanto) mounting solution. The preparations were examined in a Leitz Orthoplan microscope equipped with epifluorescence illumination using $16 \times, 50 \times$ oil, and $100 \times$ oil objectives. micrographs were taken using a Kodak Tmax 400 film exposed at 1600 ASA. This processing provided a clear and detailed view of such actin-rich structures as the stereocilia, cuticular plate and adherens-type intercellular junctions.

\section{Scanning electron microscopy (SEM)}

The tissue was fixed in $2 \%$ glutaraldehyde in $0.15 \mathrm{M}$ cacodylate buffer at $\mathrm{pH} 7.4$ for $90 \mathrm{~min}$, rinsed in buffer, post-fixed in $1 \%$ osmium tetroxide and dehydrated in alcohol. Specimens were critical point dried, sputter coated and analyzed in an Amray 1000B scanning microscope. SEM preparation enabled a high resolution analysis of the surface of the TM and the cochlear epithelium.

Fig. 1. SEM micrographs of control (group 1) avian cochleae, showing the surface of the sensory epithelium after removing the TM (A and B) or with the TM in situ (C). (A) Hair cells and supporting cells which together compose the auditory epithelial mosaic in the proximal region of the cochlea. The arrow points to the inferior aspect. hf- area corresponding to the higher frequency ( $2.2 \mathrm{kHz}$ ) used in this study. If- area of lower frequency $(1.5 \mathrm{kHz})$. (B) The well-organized mosaic of hair cells and supporting cells in the $1.5 \mathrm{kHz}$ region. Each hair cell has a bundle of stereocilia (*). Five to seven supporting cells (arrow-head) surround each hair cell. The narrow apical processes of supporting cells are covered by microvilli. (C) The TM covers the entire surface of the epithelial mosaic like a mesh. s- short hair cell region, t- tall hair cell region. Scale bars: (A) $50 \mu \mathrm{m}$; (B) $10 \mu \mathrm{m}$; (C) $5 \mu \mathrm{m}$. 
is

hf

v

If

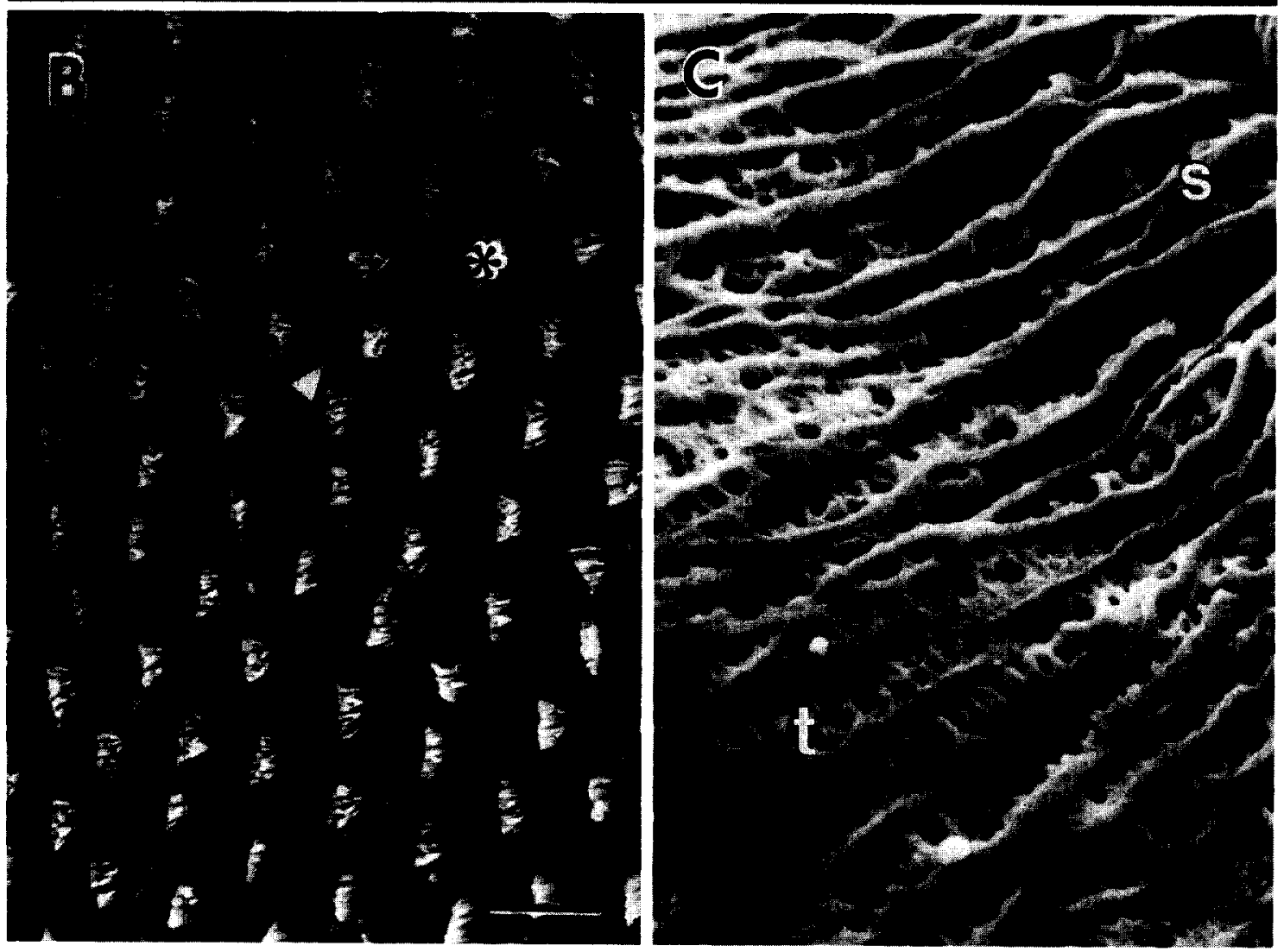


Plastic sections

Specimens were fixed as described for SEM but the tegmentum vasculosum and the TM were not removed. The entire auditory organ, without its bony shell, was embedded in Epon. One- $\mu \mathrm{m} \mathrm{sec-}$ tions were obtained with an LKB Ultrotome V microtome, using glass knives. Sections were stained with toluidine blue and examined with a Leitz Dialux microscope.

\section{Results}

Controls (group I)

SEM view of the surface revealed the cellular components of the epithelial mosaic in the proximal third of the cochlea (Fig. 1A). In normal animals, the TM had to be removed to visualize the surface of the epithelial mosaic. This portion of the cochlea includes the regions which corre-
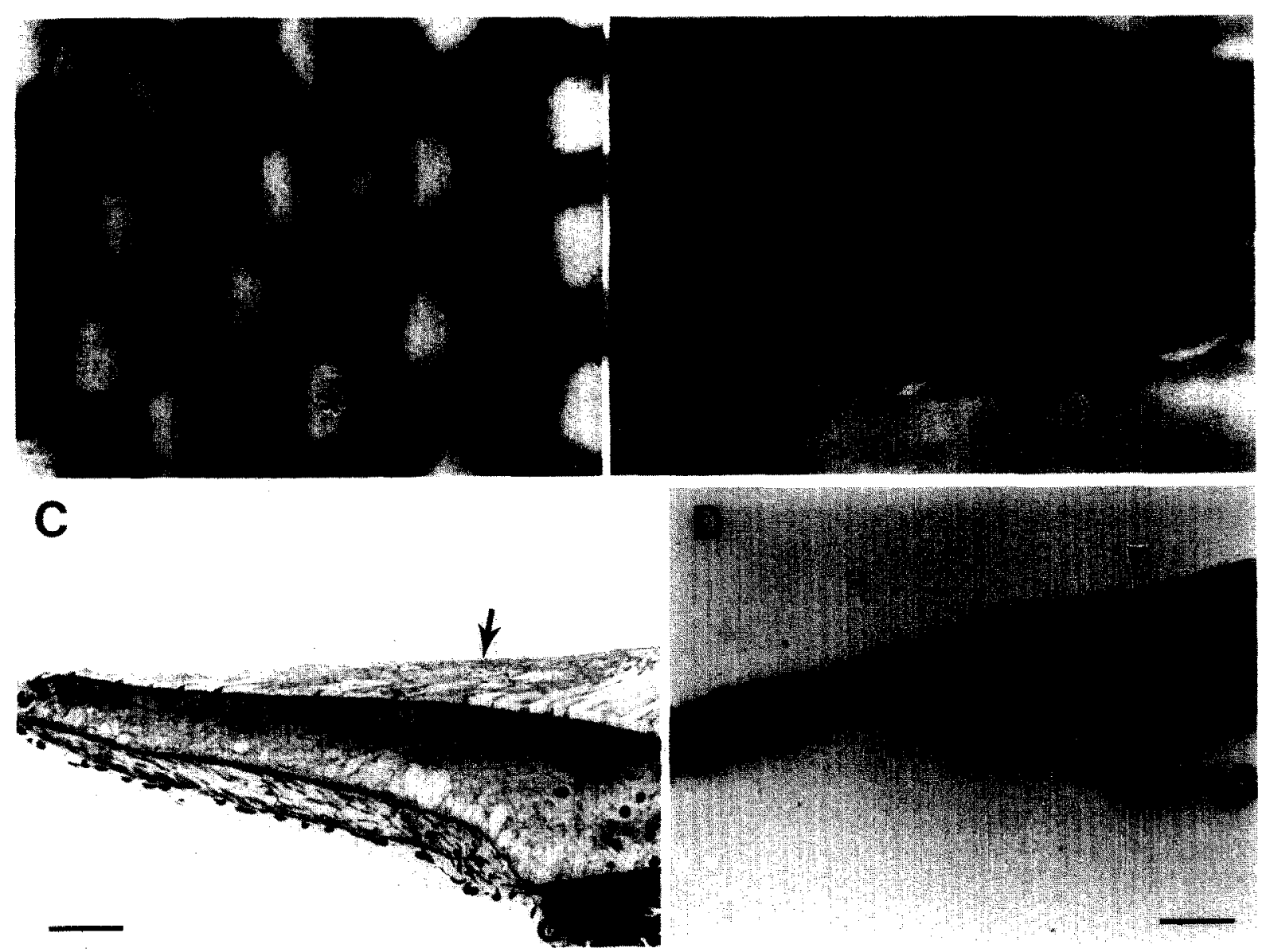

Fig. 2. Phalloidin-labeled cochleae (A and B) and LM sections cut perpendicular to the long axis (C and D) of normal (group 1) chicks. (A) Actin-specific staining is seen in staircase-arranged stereocilia (*), in the cuticular plate (arrow) and in adherens junction belts (arrow head) in the $1.5 \mathrm{kHz}$ region. (B) In the region corresponding to $2.2 \mathrm{kHz}$ the pattern of actin staining is present in similar areas but the bundles of stereocilia are shorter and the cells are of different shape. (C) LM section showing the auditory epithelium and the TM (arrow) in the $1.5 \mathrm{kHz}$ region. (D) A higher magnification light micrograph shows contact of TM-stereocilia bundle (arrow-head) and TM-supporting cell (arrow). Scale bars: (A) $10 \mu \mathrm{m}$; (B) $5 \mu \mathrm{m}$; (C) $20 \mu \mathrm{m}$; (D) $10 \mu \mathrm{m}$. 
spond to the two pure-tone frequencies used to overstimulate the sensory epithelium. Higher magnification of the region corresponding to $1.5 \mathrm{kHz}$ showed well-organized hair cells, each with a bundle of stereocilia. Apical processes of supporting cells were interposed between the hair cells (Fig. 1B). The surface of the supporting cells was identified by the microvilli which project from their apical membrane. When the TM was not removed, it covered the entire surface of the epithelial mosaic, so that neither supporting cells nor hair cells could be seen (Fig. 1C).

Surface view of phalloidin-labeled cochleae from normal chicks revealed a fine and detailed actin-specific staining in the stereocilia and the cuticular plate of hair cells as well as in the belt of intercellular adherens junctions (Fig. 2A). This distribution of staining was found in all hair cells and was therefore used as a primary marker for the presence of normal-appearing cells. In the 1.5 $\mathrm{kHz}$ region, the pattern of labeling revealed a 'staircase' organization of the bundle of stereocilia (Fig. 2A). In the proximal area, which included the region corresponding to $2.2 \mathrm{kHz}$ (Fig. 2B), the bundles of stereocilia were short, as compared with the $1.5 \mathrm{kHz}$ area (Fig. 2A), and the apical surfaces of the hair cell were elongated in the proximal-distal direction.

LM-sections of the cochlea revealed the normal appearance of the avian auditory epithelium (Fig. 2C and D). The TM covered the entire epithelial mosaic.

\section{Exposure to $1.5 \mathrm{kHz}$ (group 2)}

This exposure typically produced a lesion which was most pronounced in the area of short hair cells (Fig. 3A). Its distance from the proximal end (in \% total length) was $30 \%$. SEM-based surface analysis of the $1.5 \mathrm{kHz}$ region revealed significant damage to hair cells. The boundaries between cells were no longer clear, because of the uniform blanket of microvilli in damaged areas (Fig. 3B), making it difficult to distinguish between damaged hair cells and supporting cells.

LM sections through the region corresponding to $2.2 \mathrm{kHz}$ showed no missing hair cells. In contrast, the short hair cell region was not covered by the TM (Fig. 3C). SEM view of the $2.2 \mathrm{kHz}$ region showed that hair cells appeared relatively normal.
The TM covered the surface of supporting cells but the tips of the stereocilia on hair cells were not covered by TM (Fig. 3D). With the exposure parameters used, the damaged area of the TM extended far beyond the damaged hair cell area. The TM damage covered almost the entire proximal (basal) half of the cochlea (Fig. 4).

Actin-specific labeling revealed significant changes in the pattern of actin distribution in the $1.5 \mathrm{kHz}$ region (Fig. 5A). The absence of labeling in stereocilia and cuticular plate suggested that hair cells had been injured and may have been replaced by supporting cells, at least at the surface of the mosaic. A higher magnification micrograph showed clearly that the intercellular borders were irregular and that several cells had an atypical pattern of actin staining (Fig. 5B). The pattern of actin labeling did not change in the epithelial mosaic in the $2.2 \mathrm{kHz}$ region, confirming that no hair cell loss or injury occurred in this region (Fig. 5C).

Taken together, group 2 exposures caused damage to hair cells in the $1.5 \mathrm{kHz}$ region, and damage to the TM throughout the proximal half of the cochlea.

\section{Exposure to $2.2 \mathrm{kHz}$ (group 3)}

Overstimulation with a $2.2 \mathrm{kHz}$ pure tone resulted in a lesion in the $2.2 \mathrm{kHz}$ region, $10 \%$ from the basal end of the cochlea (Fig. 6A). The change in the pattern of actin staining was similar to that observed in group 2. LM sections confirmed that several hair cells were absent in the short hair cell region. In addition, the TM had partly degenerated, leaving the area of hair cell lesion uncovered (Fig. 6B). SEM analysis revealed hair cells in various stages of degeneration (Fig. 6C).

- In contrast to the $2.2 \mathrm{kHz}$ region, the $1.5 \mathrm{kHz}$ region appeared normal after the $2.2 \mathrm{kHz}$ exposure. The organization of the mosaic and the distribution of actin in the hair cells resembled these in control cochleae (Fig. 6D, compare with $2 A)$. SEM revealed a normal organization of hair cells in this region (Fig. 6E).

Exposure to $1.5 \mathrm{kHz}$ followed by $2.2 \mathrm{kHz}$ (group 4)

When chicks were exposed to $2.2 \mathrm{kHz}$ after priming with the first exposure, no hair cell loss occurred in the $2.2 \mathrm{kHz}$ region (Fig. 7). Low 


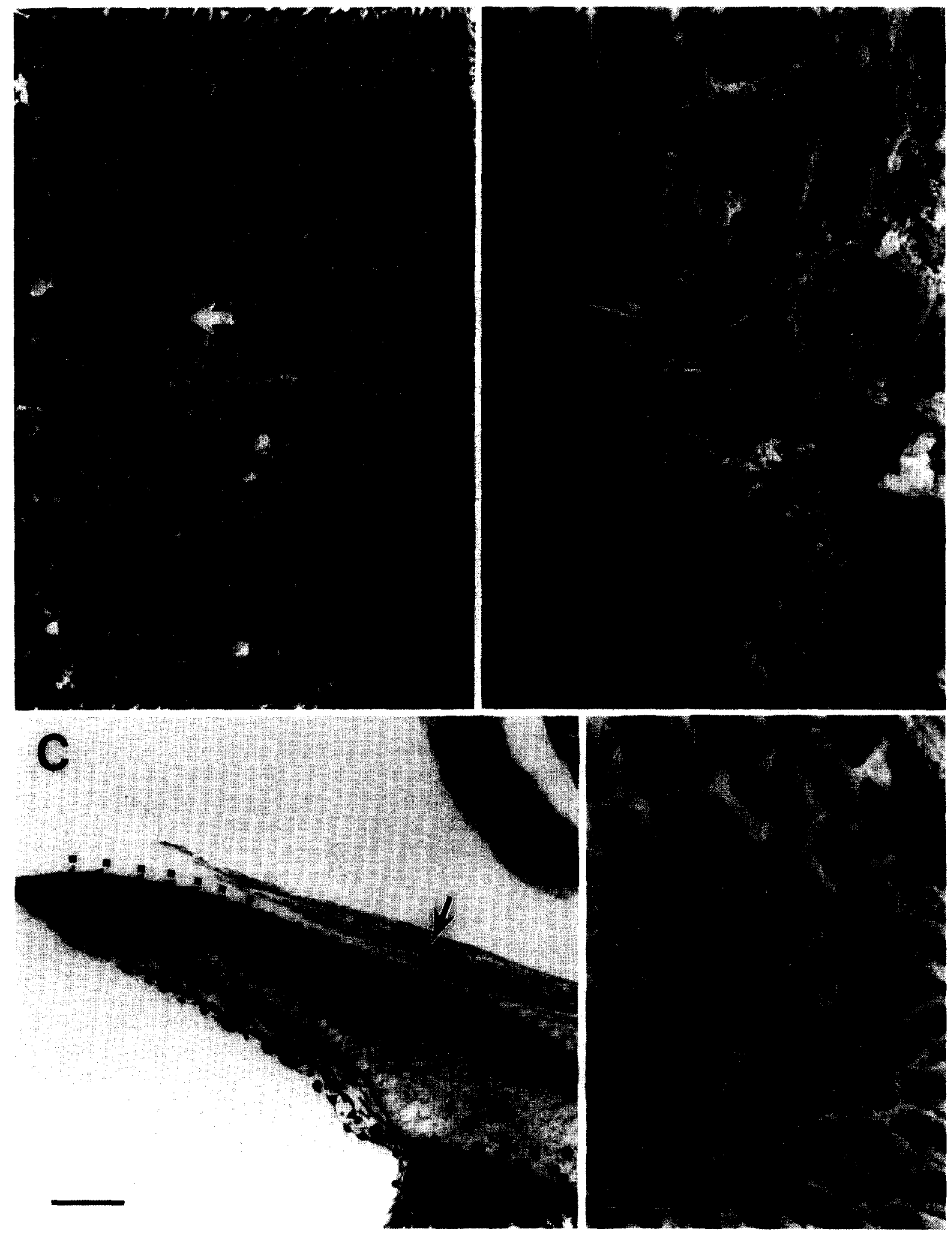




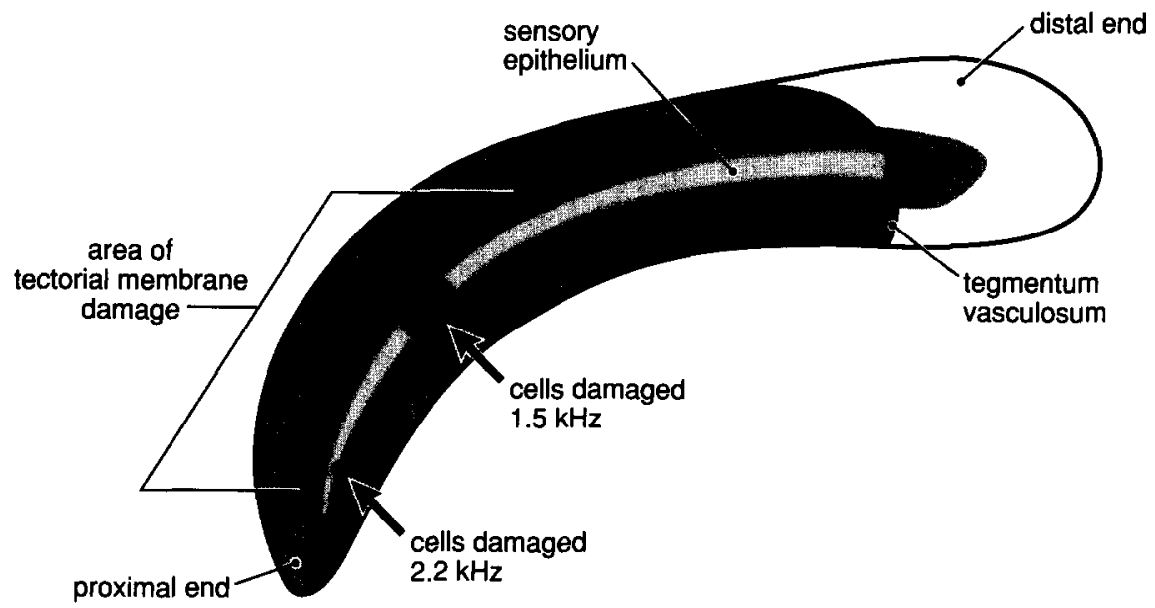

Fig. 4. Summary diagram showing the areas where hair cells and TM were damaged in the present experiments. When overstimulated with a $1.5 \mathrm{kHz}$ tone (groups 2 and 4), cells were damaged in the $1.5 \mathrm{kHz}$ area (arrow), and the TM was damaged in a greater area, as shown. When $2.2 \mathrm{kHz}$ tones were used (group 3), cells were danaged in the $2.2 \mathrm{kHz}$ area (arrow). When a $2.2 \mathrm{kHz}$ tone was used after a priming exposure to a $1.5 \mathrm{kHz}$ tone (group 4), no hair cell damage was seen in the $2.2 \mathrm{kHz}$ area.

magnification of this region showed a regular pattern of the mosaic without missing hair cells (Fig. 7A). Higher magnification showed that actinspecific staining in the stereocilia bundles appeared relatively unaltered, although the orientation of several cells had changed slightly and stereocilia on some hair cells appeared disorganized (Fig. 7B). LM sections showed that no hair cells were missing in the $2.2 \mathrm{kHz}$ area. The TM did not cover hair cells in the region (Fig. $7 \mathrm{C}$ ). SEM examination revealed that hair cells were present in the $2.2 \mathrm{kHz}$ area, but there was a significant amount of debris on the surface of the epithelial mosaic as well as several remaining strands of TM (Fig. 7D).

\section{Discussion}

Overstimulation of the cochlea with a pure-tone stimulus may produce severe damage in a specific region (group 2). However, pre-exposing the cochlea to a priming pure tone of a different frequency appears to have a protective effect on it (group 4). The damage to the TM and the hair cells following the first (priming) pure-tone exposure (group 2) is similar to that shown in previous studies using pure-tone stimuli (Cotanche, 1987a,b). The lesion caused by the second exposure alone (group 3) is localized to an area nearer to the proximal end (base) of the cochlea, corresponding to the higher frequency $(2.2 \mathrm{kHz})$.

Overstimulation of the mammalian cochlea has also been shown to result in TM changes (Canlon, 1987), although they are not as extensive as in the chick cochlea. It is likely that damage to the TM is related to mechanical overstimulation, since damage in the TM is not observed after drug-induced cochlear lesions (Cruz et al., 1987). It is necessary to determine whether the TM is sensitive to intense sounds, or whether injury to the

Fig. 3. SEM (A, B and D) and LM (C) micrographs of avian cochlea exposed to a $1.5 \mathrm{kHz}$ pure-tone. (A) The '1.5 kHz area', located $30 \%$ (of total cochlear length) away from the proximal end, was significantly damaged (arrow points to short hair cell region). (B) Higher magnification of the $1.5 \mathrm{kHz}$ area reveals degenerating hair cells as well as extensive cell surfaces densely covered with microvilli. (C) A tangential LM section of the ' $2.2 \mathrm{kHz}$ area', located approximately $10 \%$ distance from the proximal end, where the TM (arrow) covers the tall hair cell area but several short hair cells (rectangular dots) appear uncoupled from the TM. (D) SEM micrograph of the $2.2 \mathrm{kHz}$ area showing that the surface of hair cells, including bundles of stereocilia (arrow-head), are not in contact with the TM (compare with Fig. 1C). Meshwork of the TM covers the supporting cell surfaces (arrow). Scale bars: (A) 20 $\mu \mathrm{m}$; 


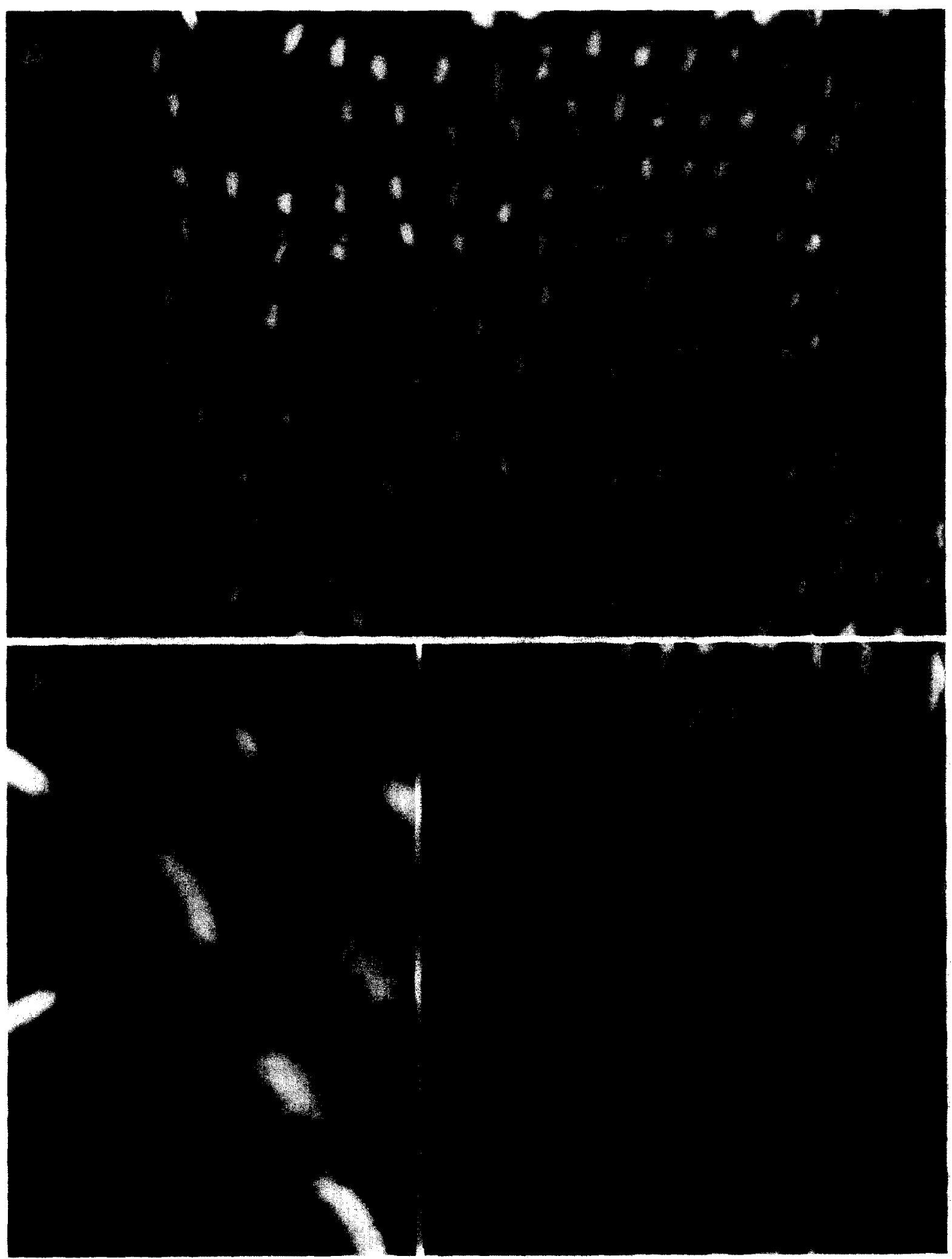


TM is secondary to injury of other tissue elements.

The microfilament network was chosen to assess the condition of the cells. Microfilaments are exceptionally prominent in the cochlear sensory epithelium and play an important role in the physiology and pathology of the cochlea. Microfilament organization in the stereocilia and the cuticular plate is known to change very early during hair cell injury (Saunders et al., 1985; Tilney et al., 1982). In addition, major changes take place in the expression of microfilaments in the reticular lamina when hair cells degenerate (Raphael and Altschuler, 1991). In the present work, only minor changes were detected in the microfilament network or in the surface morphology of hair cells in the proximal (protected) end of the cochlea, while major changes were observed in the TM. Therefore, based on the finding that major changes occur in the TM, it is speculated that these changes are responsible for the protective effect of the priming exposure. It is likely that in the absence of the TM, functional properties of short hair cells are changed, as suggested by McFadden and Saunders (1989). These changes may possibly account for the reduced susceptibility of hair cells to mechanical overstimulation.

Alternative explanations for the 'protective' effect exist. It is possible that the protection is due to cellular changes which could not be detected by the methods used in this study. In addition, protection from increased middle ear muscle activity cannot be ruled out, although such protection is unlikely to be effective at higher frequencies, as suggested by results in mammals (Borg and Nilsson, 1984).
In this study, pathological changes after tone insults which damaged short hair cells were not seen in tall hair cells. Tall hair cells survived the overstimulation despite their extensive coupling to the TM. The difference in resistance between the two cell types may be related to functional differences between them. Considering that tall hair cells are probably the transducer cells while short hair cells function as effector cells, modulating the input to the transducer cells, it is intriguing that tall hair cells are more resistant to trauma, even when the TM is normally coupled to their stereocilia. To explain this, one may assume that the effector (active) system is the first to be affected during acoustic trauma, as suggested by Puel et al. (1988). In the present study, therefore, the priming exposure also may have reduced the sensitivity of the tall hair cells, by its effect on the active system.

Protective effects of pre-exposure have been previously reported in the guinea-pig (Canlon et al., 1988). Despite differences in species and experimental design between the two investigations, the mechanisms underlying the observed protective effect may be similar. Further experiments are necessary to reveal the physiological basis for protection by priming exposure. It is also important to determine whether the mechanisms for temporary auditory threshold shifts are related to the mechanism of protection. If so, acoustic protection due to priming may serve not only as an experimental tool for better understanding the structure and function of the hearing system, but may also be used for the development of diagnostic and preventive clinical applications.

Fig. 5. Surface view of phalloidin-labeled whole mounts of group 2 cochleae Actin-specific staining is found in stereocilia, adherens junctions and cuticular plates. (A) Significant changes in actin distribution are seen in the short hair cell area of the $1.5 \mathrm{kHz}$ region, indicating that several hair cells are missing (arrow). (B) Higher magnification of the same area shows the borders of the cell in the mosaic. Several hair cells are missing. (C) In the $2.2 \mathrm{kHz}$ region, all hair cells are present and the distribution of actin is normal. Scale bars: (A) $10 \mu \mathrm{m}$; (B) $5 \mu \mathrm{m}$; (C) $10 \mu \mathrm{m}$.

Fig. 6. Phalloidin labeled preparations ( $\mathrm{A}$ in the $2.2 \mathrm{kHz}$ area and $\mathrm{D}$ in the $1.5 \mathrm{kHz}$ area), $\mathrm{LM}$ section in the $2.2 \mathrm{kHz}$ area (B), and SEM specimens ( $\mathrm{C}$ in the $2.2 \mathrm{kHz}$ area and $\mathrm{E}$ in the $1.5 \mathrm{kHz}$ area) of cochleae exposed to a $2.2 \mathrm{kHz}$ pure-tone (group 3). (A) The pattern of actin distribution in the $2.2 \mathrm{kHz}$ area indicated that several hair cells are missing (arrow). (B) Several short hair cells are missing (arrows). (C) SEM micrograph showing hair cells in different stages of degeneration. (D and E) In the $1.5 \mathrm{kHz}$ area no cells are absent and the distribution of actin is normal. Scale bars: (A) $10 \mu \mathrm{m}$; (B) $10 \mu \mathrm{m}$; (C) $10 \mu \mathrm{m}$; (D) $2 \mu \mathrm{m}$; (E) $5 \mu \mathrm{m}$. 


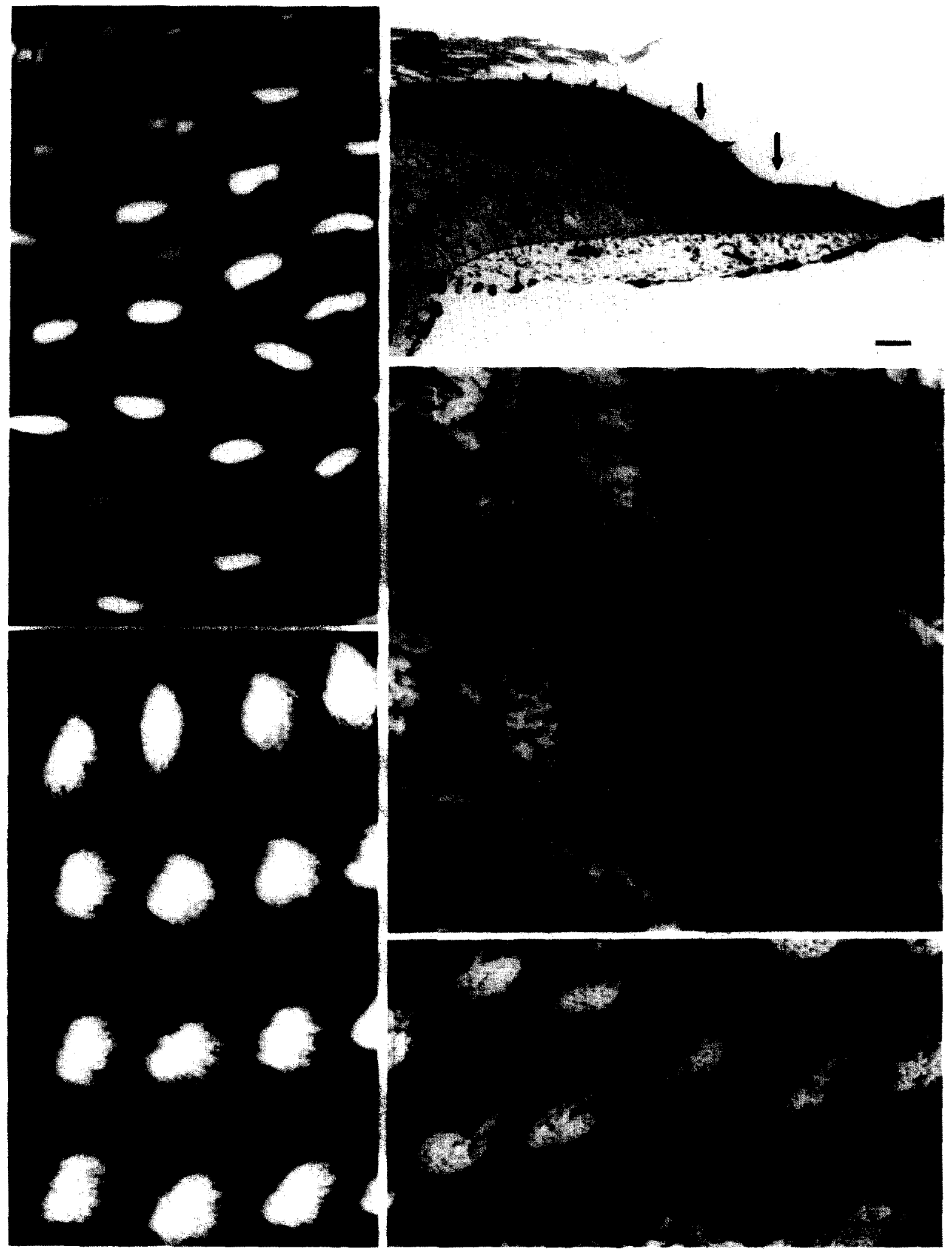




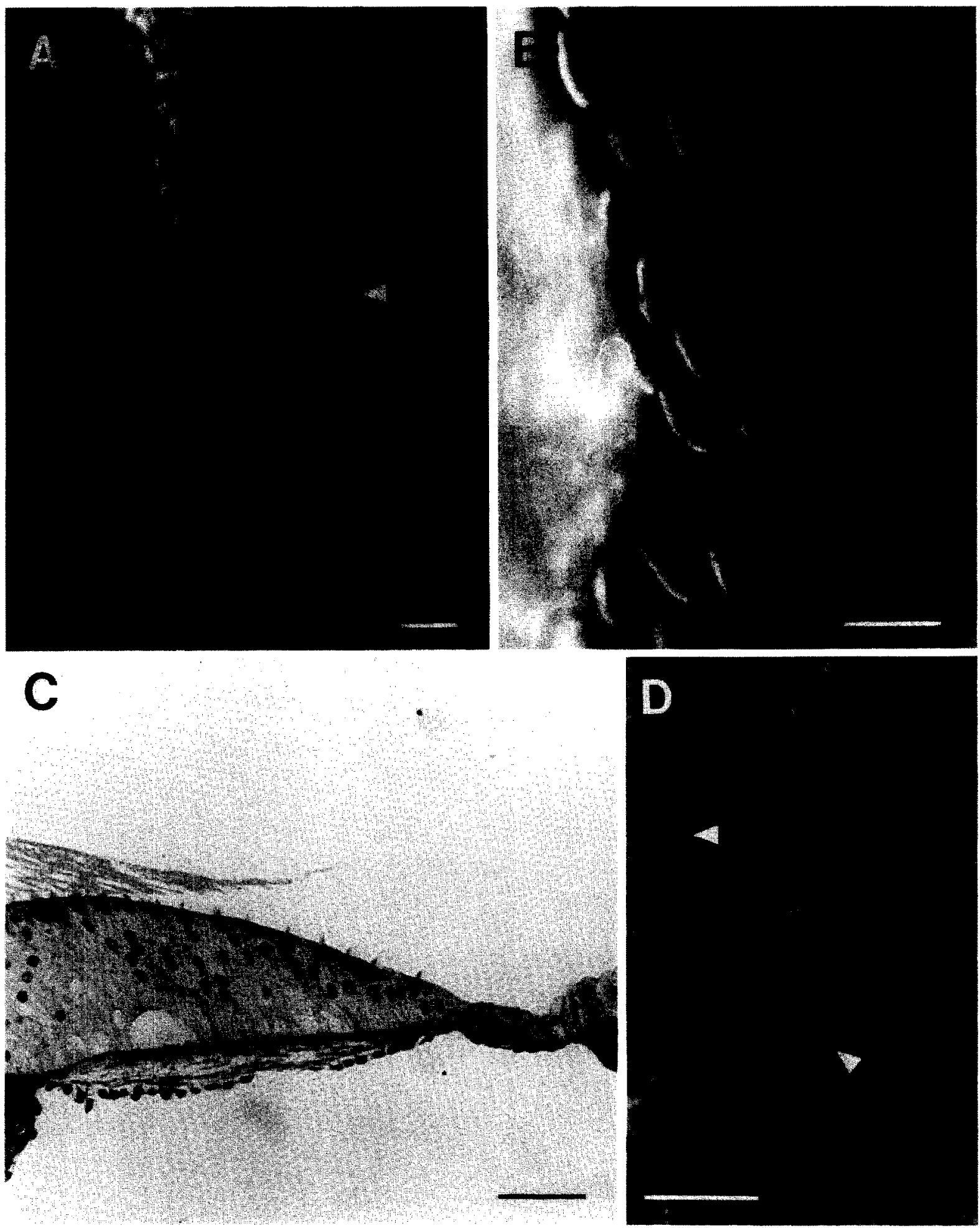

Fig. 7. Phalloidin-labeled preparations (A and B), LM section (C) and SEM micrograph (D) of group 4 cochleae exposed to pure tones of $1.5 \mathrm{kHz}$ followed by $2.2 \mathrm{kHz}$. (A) Low magnification fluorescence micrograph of the proximal end of the cochlea. No hair cell loss can be seen in the $2.2 \mathrm{kHz}$ region (arrow). (B) Higher magnification micrograph of the same area, showing normal organization of stereocilia in this region. (C) No hair cell loss is seen in this LM section. The TM does not entirely cover the short hair cell region. (D) When the TM is not removed in preparation, residual meshes can be seen in the $2.2 \mathrm{kHz}$ area but the stereocilia of hair cells (arrow-heads) are not attached to it. Scale bars: (A) $20 \mu \mathrm{m}$; (B) $10 \mu \mathrm{m}$; (C) $20 \mu \mathrm{m}$; (D) $10 \mu \mathrm{m}$. 


\section{Acknowledgments}

The author wishes to thank Drs. Joseph Hawkins, Cynthia Prosen and Susan Shore for critically reviewing the manuscript. The excellent technical assistance of Ms. Linda Gafney and Mr. Robert Masta is greatly appreciated. This work was supported by NIH grant NS 05785 .

\section{References}

Borg, E. and Nilsson, R. (1984) Acoustic reflex in industrial noise. In: S. Silman (Ed.), The Acoustic Reflex: Scientific Aspects and Clinical Application, Academic Press, pp. $413-440$.

Canlon, B. (1987) Acoustic overstimulation alters the morphology of the tectorial membrane. Hear. Res. 30, 127-134.

Canlon, B., Borg, E. and Flock, §. (1988) Protection against noise trauma by pre-exposure to a low level acoustic stimulus. Hear. Res. 15, 197-200.

Cotanche, D.A. (1987a) Regeneration of hair cell stereociliary bundles in the chick cochlea following severe acoustic trauma. Hear. Res. 30, 181-196.

Cotanche, D.A. (1987b) Regeneration of the tectorial membrane in the chick cochlea following severe acoustic trauma. Hear. Res. 30:197-206.
Cruz, R.M., Lambert, P.R. and Rubel, E.W. (1987) Light microscopic evidence of hair cell regeneration after gentamicin toxicity in chick cochlea. Arch. Otolaryngol. Head Neck Surg. 113, 1058-1062.

McFadden, E.A. and Saunders, J.C. (1989) Recovery of auditory function following intense sound exposure in the neonatal chick. Hear. Res. 41, 205-216.

Puel, J.L., Bobbin, R.P. and Fallon, M. (1988) The active process is affected first by intense sound exposure. Hear. Res. 37, 53-64.

Raphael, Y., Horn, J. and Altschuler, R.A. (1989) Changes in the tectorial membrane, adhesion molecules and cytoskeletal proteins during degeneration and regeneration of chicken hair cell. XXVI Workshop on Inner Ear Biology, Paris, France.

Raphael, Y. and Altschuler, R.A. (1991) Scar formation after drug induced cochlear insult. Hear. Res. 51, 173-184.

Saunders, J.C., Dear, S.P. and Schneider, M.E. (1985) The anatomical consequences of acoustic injury: A review and tutorial. J. Acoust. Soc. Am. 78, 833-860.

Tilney, L.G., Saunders, J.C., Egelman, E. and DeRosier, D.J. (1982) Changes in the organization of actin filaments in the stereocilia of noise-damaged lizard cochleae. Hear. Res. 7 , $181-197$.

Tilney, L.G., Tilney, M.S. and Cotanche, D.A. (1988) New observations on the stereocilia of hair cells of the chick cochlea. Hear. Res. 37, 71-82. 